\title{
Modeling for anthracnose development in mango in relation to weather parameters
}

\author{
Rajender Singh ${ }^{1} \cdot$ Deepankar $^{2}$
}

Received: 21 August 2019 / Accepted: 6 April 2020 / Published online: 23 April 2020

(C) The Author(s) 2020

\begin{abstract}
Mango anthracnose severity on leaves was recorded at 14 day intervals throughout the year 2013, 2014, 2015, 2017 and 2018 on mango cultivar Dashaheri. Logistic model was best for the year 2013, 2014, 2015, 2018 and pooled data of these years had lower mean square error (MSE) 37.67, 91.29, 100.84, 65.80 and 72.32 along with high coefficient of determination (R(Dodd et al. 1991) $0.753,0.532,0.534,0.656$ and 0.606 , respectively. Maximum anthracnose development i.e. periodical disease progression (6.9\%) was highest from 31st to 33th Standard Meteorological Weeks (SMW) because of cumulative effect of minimum temperature $\left(27^{\circ} \mathrm{C}\right)$ and morning relative humidity $(\geq 90 \%)$ along with the rainfall $(56 \mathrm{~mm})$. Mango anthracnose severity was positively and significantly correlated with the minimum temperature $(0.62)$ followed by rainfall $(0.46)$ on all year pooled data basis, whereas the highest correlation 0.65 was observed for the years 2014 and 2015 . The regression model based on pooled data has performed better an alternative regression model of each individual year with the highest adjusted $\mathrm{R}^{2}$ value i.e. 0.747 , explaining the effects of minimum temperature, morning relative humidity and rainfall on the anthracnose severity.
\end{abstract}

Keywords Mango anthracnose $\cdot$ Colletotrichum gloeosporioides $\cdot$ Gompertz model $\cdot$ Logistic model

\section{Introduction}

The mango (Mangifera indica L.) is grown throughout the tropics and subtropics worldwide. India is the world's largest producer of mango fruit which is considered as an exotic, specialty item in import markets such as the United States and Europe (www.nhb.gov.in, Dodd et al. 1992). It suffers from various biotic and abiotic stresses from transplanting to post harvest. Among them, mango anthracnose is major constraint for the production of this fruit. Mango anthracnose incited by Glomerella cingulata (Stoneman) Spauld. \& H. Schrenk is a hemibiotroph and causes disease on a wide variety of fruits, vegetables and field crops (SantosFilho and Matos 2003). In India, estimated losses of up to $39 \%$ have been attributed to anthracnose infection (Prakash 2004). Mango anthracnose is most severe at high temperature and relative humidity, attaining an incidence of

Rajender Singh

rsb1965@gmail.com

1 Department of Plant Pathology, CCS HAU, Hisar 125004, India

2 Department of statistics, CCS HAU, Hisar 125004, India almost $100 \%$ in fruits produced under very wet conditions (Arauz 2000). Therefore, there is a higher appearance of the fungus in tropical and subtropical countries, and the necessity of controlling the disease increases the production cost. The pathogen also causes leaf, blossom and twig blight and in severe cases, tree dieback. Conidia are formed abundantly in the mango canopy and thus are considered primary source of inoculum. In the orchard, conidia produce lesions on leaves, twigs, panicles, and mummified fruit (Ploetz et al. 1996). Conidia can be rain-splashed to other leaves or flowers and cause secondary infections, thus the pathogen is polycyclic in these organs. Epidemiological models, viz. descriptive and conceptual models indicate areas where information is lacking especially, on biology of host and pathogen system. Mathematical models can be used to obtain information about the appearance and amount of inoculum, changes in host susceptibility during growing Period. These models may be in terms of simple or complex functions, regression equations, differential equations and simple decision models. In plant disease epidemiology, disease progress curves, linked differential equations, area under disease progress curve and computer simulations are used to understand these factors by modeling the epidemic dynamics. Mathematical model allow us to understand the processes involved in determining the 
spread of disease and allow more accurate forecasting and control of disease outbreaks. Growth models provide a range of curves that are often similar to disease progress curves (Van Maanen and Xu 2003) and represent one of the most common mathematical tools to describe temporal disease epidemics (Xu 2006). Growth models are extensively utilized for summarizing and comparing plant diseases epidemics. The growth models commonly used are: Monomolecular, Exponential, Logistic and Gompertz (Zadoks and Schein 1979; Nutter 2007; Nutter and Parker 1997; Xu 2006).Therefore, the present investigations were conducted to learn how to manage the disease through the use of growth models and disease progress curve. The knowledge can be used to minimise chemical application so that we can have chemical free organic fruits and less hazard from environmental pollutions. Gompertz and logistic growth models are appropriate for polycyclic diseases. The Gompertz model has an absolute rate curve that reaches a maximum more quickly and declines more gradually than the logistic models (Nutter 2007). The use of growth models for disease progress curves usually explain the disease progress in a better way by adding few variables (Xu 2006), but sometimes it is not adequate to describe certain kinds of pathogens, because it needs to incorporate extra variables that are determinant in the pathosystem. However, accounts on epidemiological information in relation to growth modelling of mango anthracnose are not dealt so far in India. Therefore, the current study on epidemiological aspects of statistical modelling of mango anthracnose occurrence can help the mango growers and decision makers to implement timely preventive measures thus reducing economic losses.

\section{Materials and methods}

The experiment was laid out in the experimental orchard of Chaudhary Charan Singh, Haryana, Agricultural University, Hisar (CCSHAU, $75^{\circ} 46^{\prime} \mathrm{E} 29^{\circ} 10^{\prime} \mathrm{N}$ ) and $215.2 \mathrm{~m}$. Five 20 years old plants (five branches/twigs leaves per plant in all directions North, South, East and West) of mango cultivar Dashaheri were taken for recording observations on natural anthracnose occurrence and development. There was no pruning or chemical application on these plants. Mango anthracnose severity was recorded on Standard Meteorological Week (SMW) basis at 14 day intervals throughout the year 2013, 2014, 20152017 and 2018 on susceptible mango cultivar Dashaheri. Mango anthracnose severity was correlated and regressed against prevailing weather parameter during corresponding period of each year. The weather data recorded at the Agri-meteorological observatory located at CCSHAU Hisar research farm. The growth models like Gompertz, and Logistic for development of disease severity were fitted. The descriptions of these models are appended.

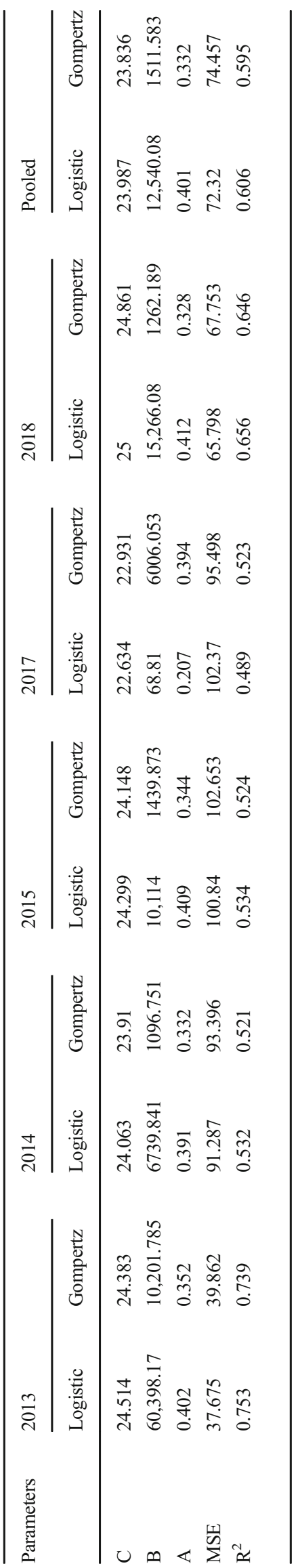


Fig. 1 Observed versus predicted anthracnose severity (2013)

Fig. 2 Observed versus Predicted anthracnose severity (2014)

Fig. 3 Observed versus Predicted anthracnose severity (2015)
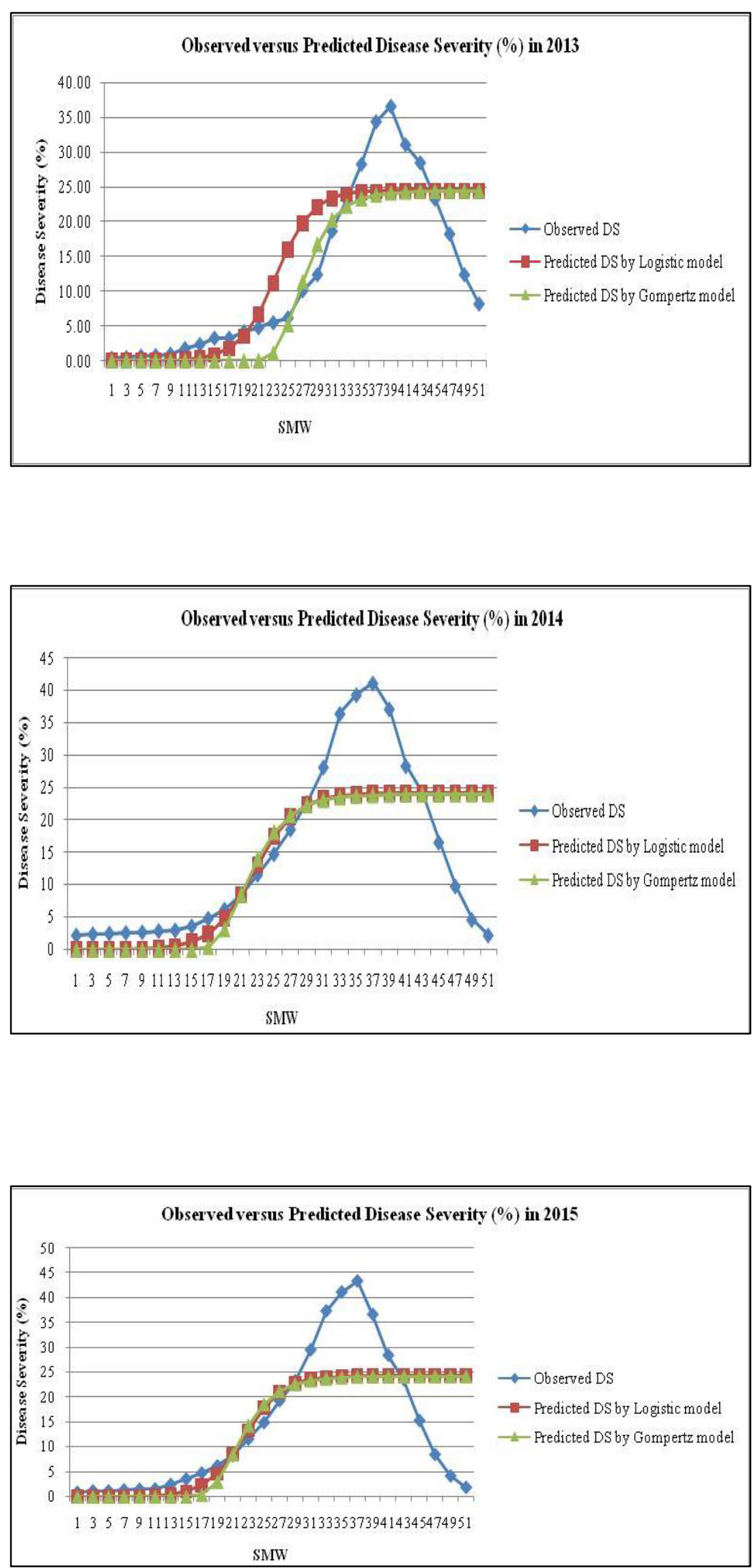
Fig. 4 Observed versus Predicted anthracnose severity (2017)

Fig. 5 Observed versus Predicted anthracnose severity (2018)

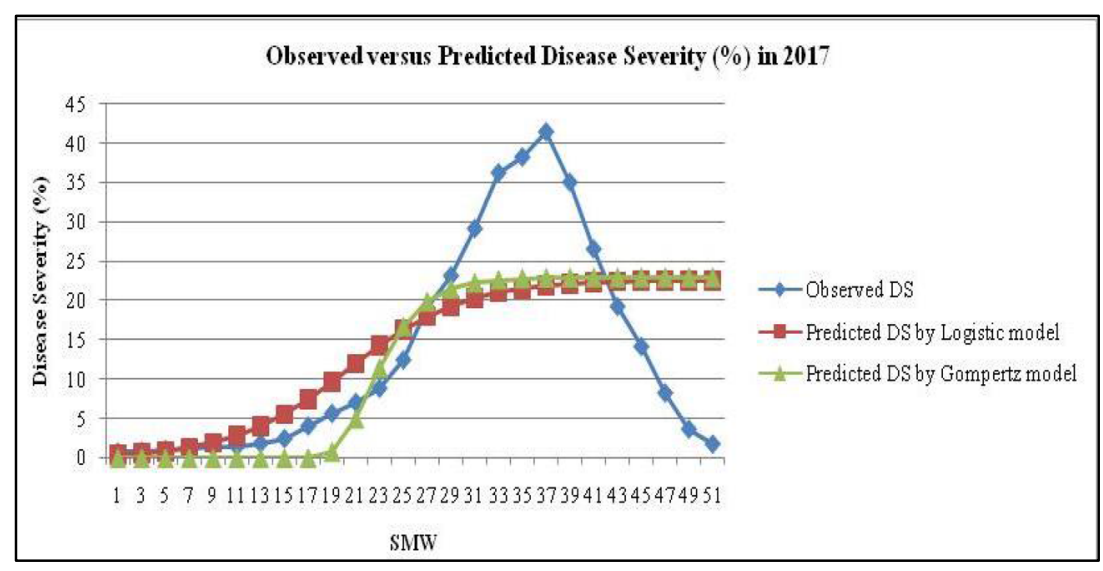

Logistic model: The Logistic model assumes that the absolute rate of change in disease level depends on both healthy tissue $(y)$ and diseased tissue (1-y) present at the time. The curve is perfectly symmetric with an inflection point at $t=1$ /
Observed versus Predicted Disease Severity (\%) in 2018

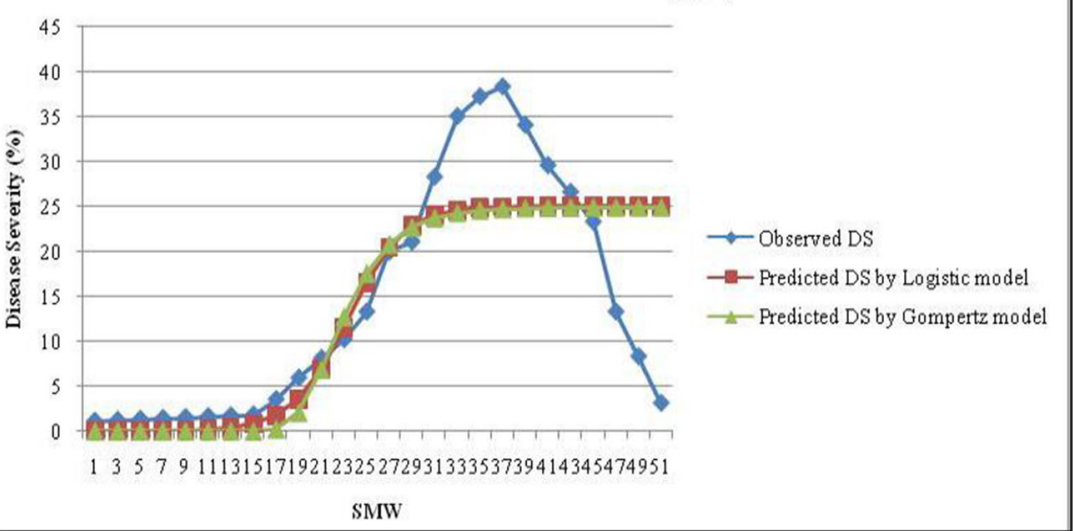

Fig. 6 Observed versus Predicted anthracnose severity (2013-18) $r \ln y_{0} /\left(1-y_{0}\right)$, when $y=1 / 2$. That is, $d y / d t$ increases up until $y=1 / 2$ and decreases thereafter. $f(x)=\mathrm{c} /(1+\mathrm{b} * \exp .(-\mathrm{a} * \mathrm{t}))$.

It was proposed by Van der Plank (1963), being more appropriate for most polycyclic diseases as there is a secondary

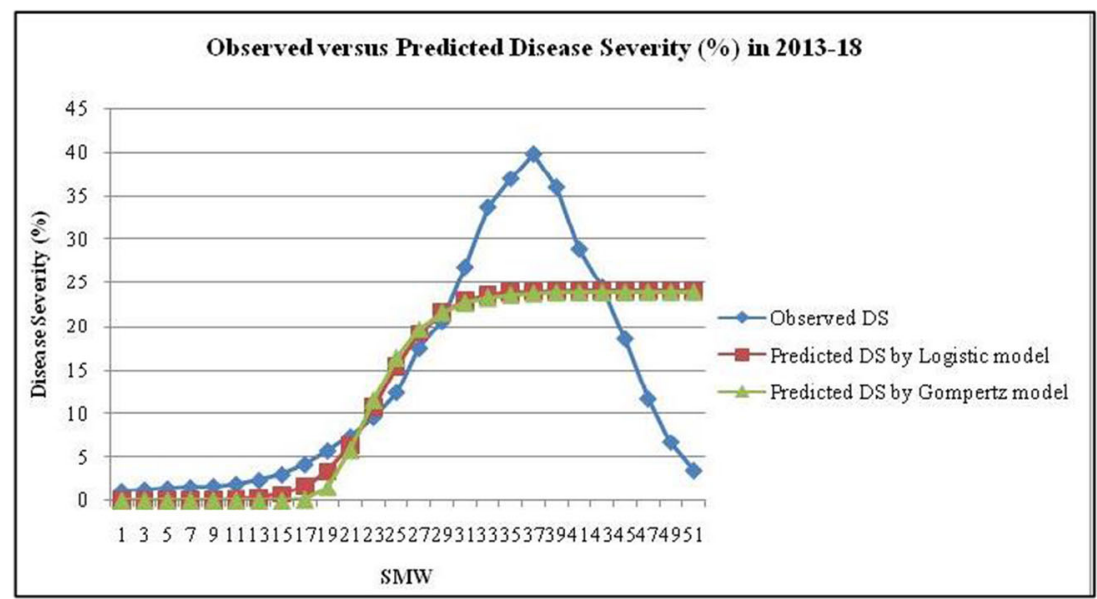




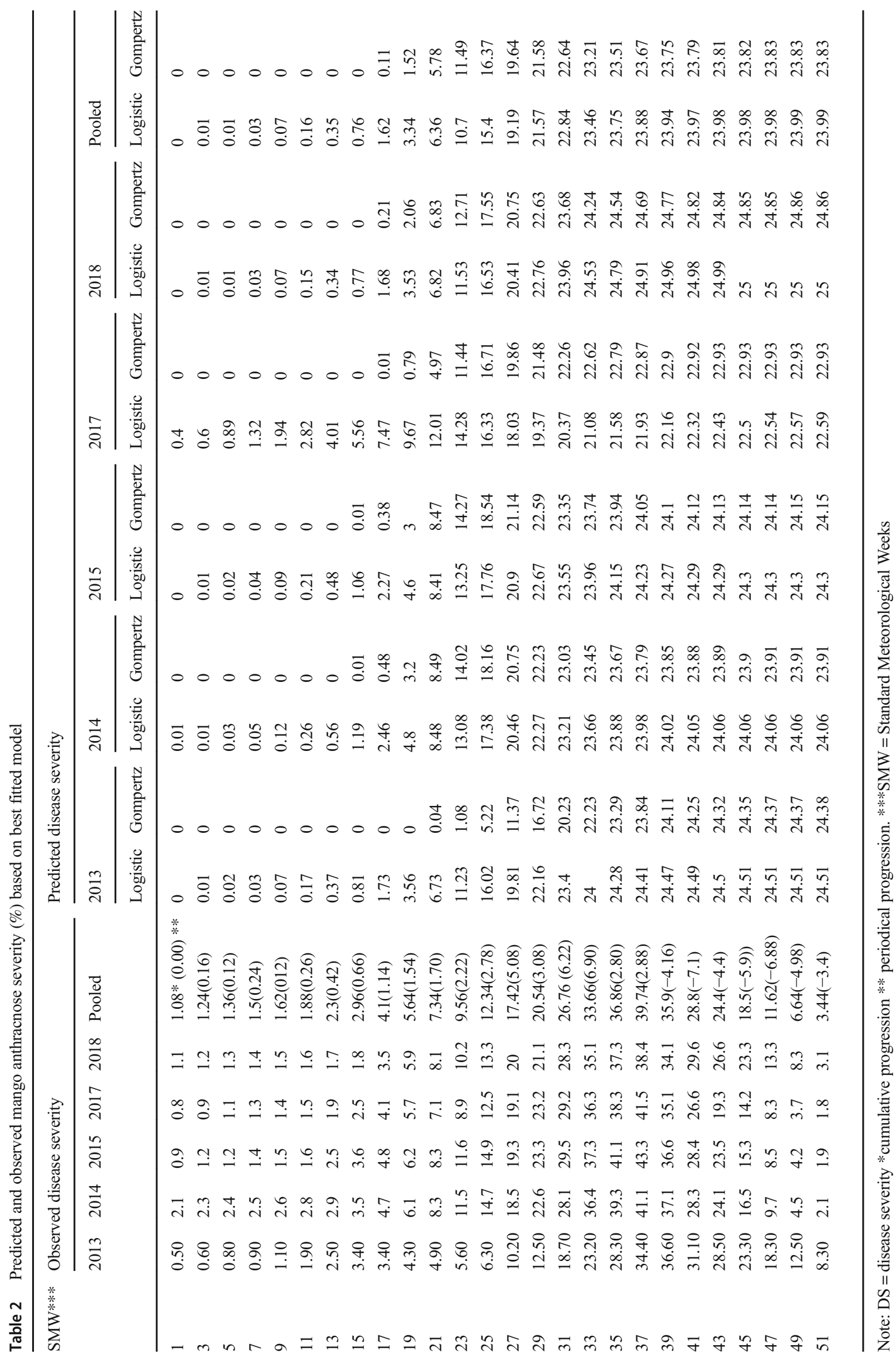


Table 3 Descriptive statistics for the mango anthracnose with weather parameters.

\begin{tabular}{lllllllll}
\hline Year & & Disease severity & Tmax & Tmin & Rhm & Rhe & SS & Rainfall \\
\hline \multirow{2}{*}{2013} & Mean & 12.39 & 31.06 & 18.98 & 83.31 & 48.31 & 4.19 & 30.92 \\
& S.D. & 11.86 & 7.03 & 7.67 & 14.48 & 15.75 & 2.57 & 49.60 \\
2014 & Mean & 14.41 & 30.82 & 16.94 & 82.04 & 48.00 & 7.17 & 13.73 \\
& S.D. & 13.39 & 8.12 & 8.30 & 13.04 & 16.03 & 2.02 & 15.28 \\
2015 & Mean & 14.30 & 30.86 & 17.34 & 83.19 & 48.30 & 6.90 & 24.79 \\
& S.D. & 14.09 & 7.40 & 7.63 & 12.44 & 15.01 & 1.93 & 35.19 \\
2017 & Mean & 13.31 & 31.41 & 17.25 & 83.51 & 46.25 & 6.58 & 22.68 \\
& S.D. & 13.56 & 7.11 & 8.11 & 13.56 & 17.83 & 2.02 & 52.56 \\
\multirow{2}{*}{ Pooled } & Mean & 14.27 & 31.60 & 17.27 & 82.88 & 49.12 & 6.29 & 14.45 \\
& S.D. & 13.27 & 6.77 & 8.55 & 13.59 & 14.65 & 1.31 & 28.91 \\
& Mean & 13.74 & 31.15 & 17.56 & 82.99 & 48.00 & 6.23 & 21.32 \\
& S.D. & 13.00 & 7.10 & 7.84 & 12.41 & 13.04 & 1.56 & 23.68 \\
\hline
\end{tabular}

Note: S.D. $=$ standard deviation, $\operatorname{Tmax}=\operatorname{maximum}$ temperature $\left({ }^{\circ} \mathrm{C}\right), \mathrm{Tmin}=\operatorname{minimum}$ temperature $\left({ }^{\circ} \mathrm{C}\right), \mathrm{Rhm}$ : morning relative humidity $(\%)$, Rhe $=$ evening relative humidity $(\%), \mathrm{SS}=$ bright sunshine hours, Rainfall $(\mathrm{mm})$ spread within a growing season and most widely used for describing epidemics of plant disease.

Gompertz model: The Gompertz model assumes that the absolute rate of change depends on $y$ and $\ln (1 / y)$ and is very similar to the Logistic model. However, the Gompertz model is more asymmetric, with an inflection point attained at $0.37(1 / e)$ instead. This growth model is appropriate for polycyclic diseases as an alternative to logistic model. Gompertz model has an absolute rate curve that reaches a maximum more quickly and declines more gradually than the logistic model (Nutter 2007). $f(x)=\mathrm{c}^{*} \exp .(-\mathrm{b} * \exp .(-\mathrm{a} * \mathrm{t}))$.

The description of parameter estimation gave the mean and variance of respective model.

\section{Results}

\section{Parameter estimation through mean square error for growth modelling}

It is clearly evident that the logistic model was best for the year 2013, 2014, 2015 and 2018 with lower MSE 37.67, 91.28, 100.84 and 65.80 with high coefficient of determination (R(Dodd et al. 1991)) 0.753, 0.532, 0.534 and 0.656,

Table 4 Correlation between mango anthracnose severity and weather parameters.

\begin{tabular}{llllllll} 
Crop season disease severity & Tmax & Tmin & RHm & Rhe & SS & RF \\
\hline 2013 & 0.19 & 0.57 & 0.23 & 0.3 & -0.13 & 0.4 \\
2014 & 0.5 & 0.65 & -0.18 & -0.16 & 0.28 & 0.18 \\
2015 & 0.53 & 0.65 & -0.15 & -0.06 & 0.25 & 0.13 \\
2017 & 0.39 & 0.62 & 0.21 & 0.31 & -0.08 & 0.17 \\
2018 & 0.37 & 0.61 & 0.23 & 0.5 & -0.2 & 0.47 \\
Pooled & 0.42 & 0.62 & 0.08 & 0.22 & 0.08 & 0.46
\end{tabular}

respectively, whereas for the year 2017 the Gompertz model was best with lower MSE 95.50 (Table 1) and high $\mathrm{R}^{2} 0.523$. On analysing the pooled data for best interpretation, the Logistic model performed better as compared to Gompertz model with lower MSE (72.32) and high $\mathrm{R}^{2}$ (0.606). With $5 \%$ rate of increase of disease severity, it was recorded maximum in the year 2015 ( 43.30) followed by $2017(\sim 41.50)$ and 2014 ( 41.10). In the year $2013(\sim 36.60)$ and 2018 $(\sim 38.40)$, disease severity was recorded lower than pooled disease severity $(\sim 39.74)$. The predicted values by Logistic and Gompertz models for all years as well as for pooled disease severity data have also been plotted against the observed values of disease severity of respective years (Figs. 1, 2, 3, 4, 5 and 6).

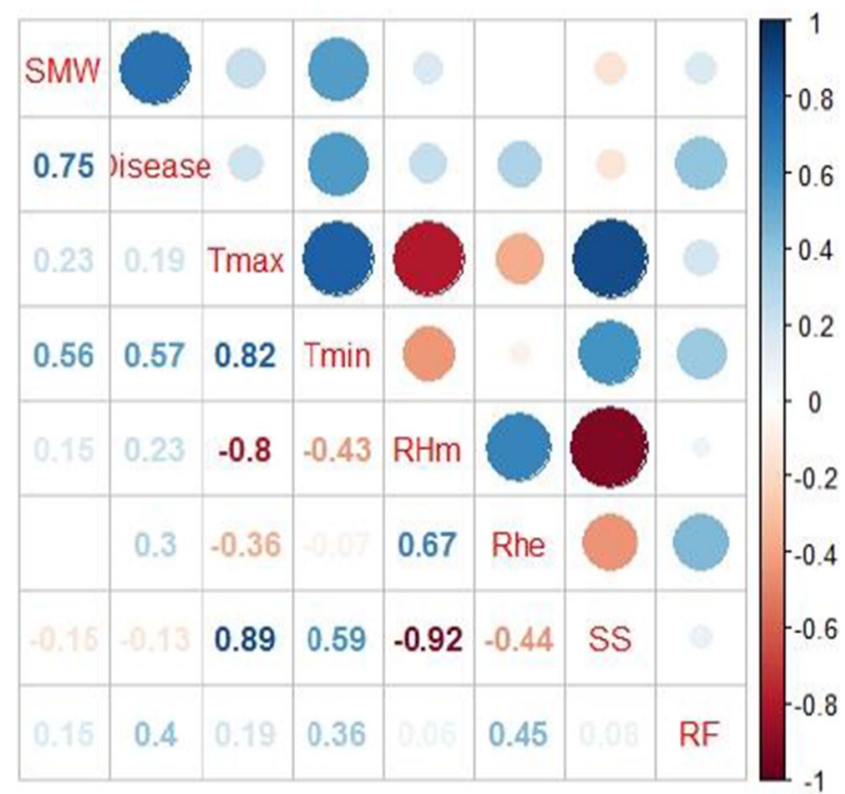

Fig. 7 Correlation between mango anthracnose severity and weather parameters (2013) 


\section{Correlation of mango anthracnose severity with weather parameters and its determinant}

Mango anthracnose severity increase was observed from 17th to 39th SMW ( Table 2). On the basis of pooled data disease severity, the maximum periodical disease progression (6.9\%) occurred in the period 31th to 33th SMW followed by 29th to 31 th SMW having $6.22 \%$ periodical disease progression ( Table 2) for which prevailing weather parameters during the corresponding period determine further spread and aggravation of this compound interest disease. Henceforth, a prevailing minimum temperature $\left(27^{\circ} \mathrm{C}\right)$ coupled with morning relative humidity ( $\geq 90 \%)$ accompanied with the rainfall $(56 \mathrm{~mm})$ during 29th to 31th SMW (Table 3 and Figs. 1, 2, 3, 4, 5 and 6) provided optimal conditions for conidia germination of C. gloeosporioides (Penz.) and exacerbation of anthracnose.

The correlation between the disease severity and weather parameters was also computed ( Table 4). The results revealed that minimum temperature (pooled value, 0.62 ) followed by rainfall (pooled value, 0.46 ) have significant positive correlation with disease severity during the year 2013, 2014, 2015, 2017 and 2018 (Table 4). Therefore, it can be concluded that the amount of rainfall received during the period of disease development (July to September) influenced temperature and relative humidity in such a way that the composite effect of all the three factors led to considerable increase in disease severity. The yearly and pooled data correlation between mango anthracnose severity with weather parameters has clearly been depicted and evident in Figs. 7, 8, 9, 10, 11 and 12. Variation in temperature requirement for conidia germination and further spread may be due to variant/isolate. It is further added that decline in anthracnose or negative periodical progression from 39th SMW onward. Pooled data of anthracnose severity plotted against time period for measuring the rate of anthracnose development is shown in Figs. 1, 2, 3, 4, 5 and 6.

The stepwise regression was used for identifying the best subset of weather variables that play crucial role in development of anthracnose. Using these variables, the regression models were generated to foretell the relationship between disease severity and weather variables ( Table 5). In 2014, the regression model with positive effect of minimum temperature, morning relative humidity and negative effect of evening relative humidity has shown highest value of adjusted $\mathrm{R}^{2}$ ( $\sim 0.741$ ) followed by regression model of 2018 with 0.694 adjusted $\mathrm{R}^{2}$ with weather parameters minimum temperature and morning relative humidity ( Table 5). The stepwise regression was performed for each year separately and then goes for pooled data. The regression model for 2014 exhibited the highest adjusted $R^{2}(\sim 0.741)$ explaining the significant positive effect of minimum temperature and morning relative humidity followed by 2018 year regression model which also express the positive relationship between the disease severity, and minimum temperature and morning relative humidity

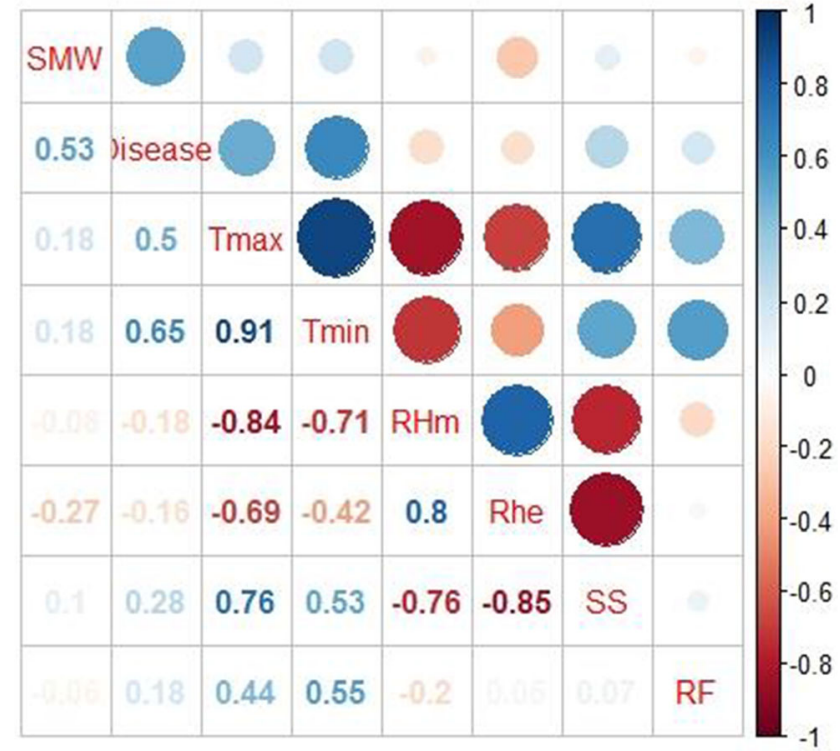

Fig. 8 Correlation between mango anthracnose severity and weather parameters (2014)

with the 0.694 adjusted $\mathrm{R}^{2}$ value. The model fitted on pooled data also presents result similar to regression model of year 2014 and 2018 in terms of adjusted $R^{2}$ and weather variables except only significant negative effect of rainfall is included in model ( Table 5). The pooled data regression model outperforms all existing respective year regression model with highest value of adjusted $\mathrm{R}^{2}$ i.e. 0.747 . Variation in temperature requirement for conidia germination and further spread may be due to variant/isolate. Pooled data of anthracnose severity plotted against time period for measuring the rate of anthracnose development is shown in Figs. 1, 2, 3, 4, 5 and 6.

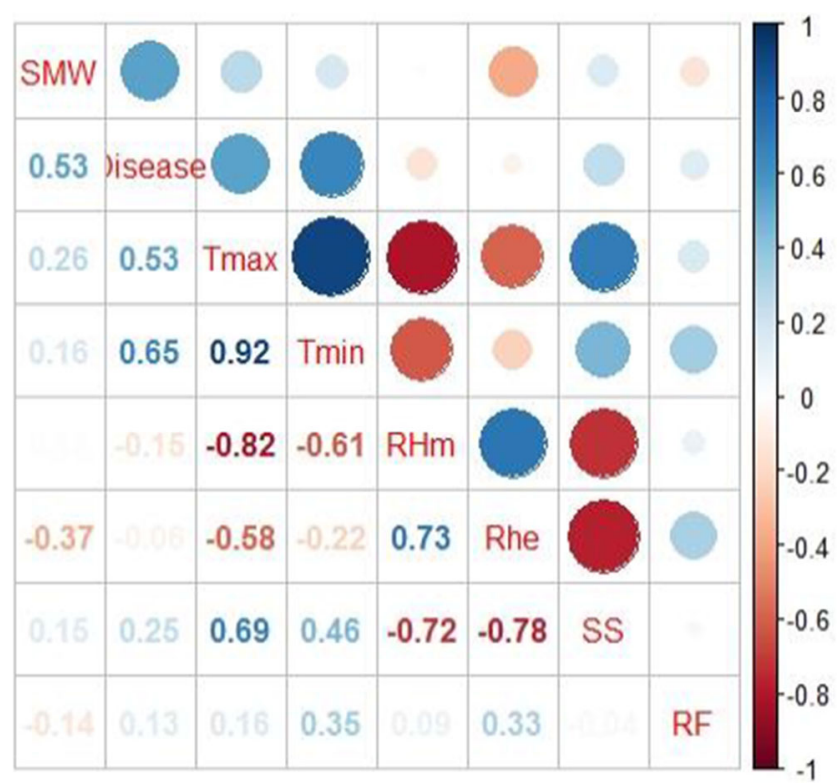

Fig. 9 Correlation between mango anthracnose severity and weather parameters (2015) 


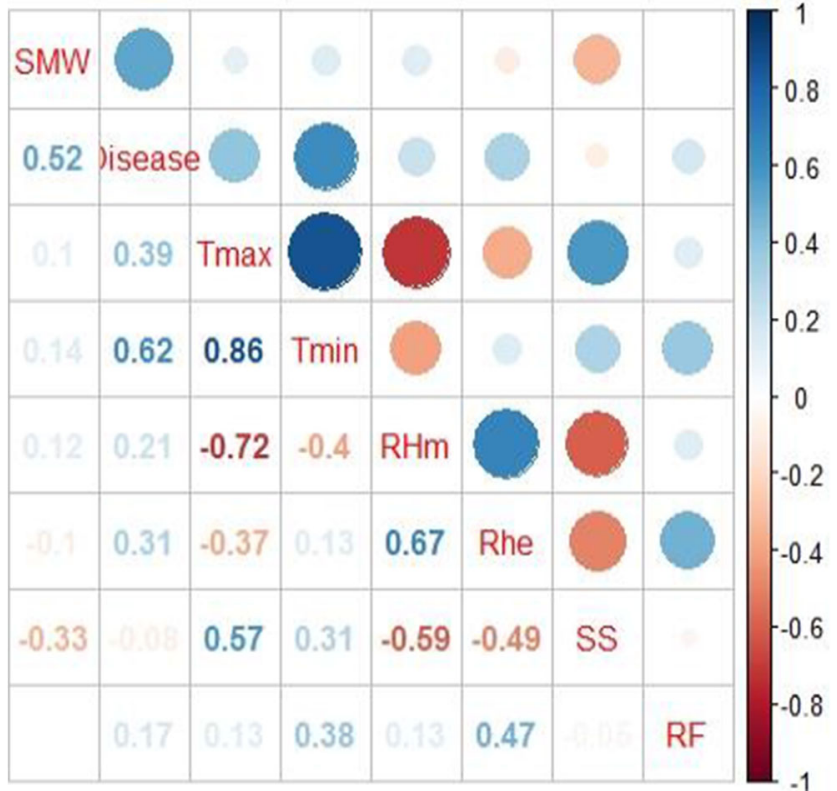

Fig. 10 Correlation between mango anthracnose severity and weather parameters (2017)

\section{Discussion}

Disease progress curves represented by growth models i.e. Gompertz and Logistic models have a characteristic sigmoid form (Figs.1, 2, 3, 4, 5 and 6) and an inflection point indicating secondary spread within the crop in contrast to monomolecular model, which does not have inflection point. The monomolecular model does not hold valid conditions for mango anthracnose since compound interest disease as the pathogen under investigations is polycyclic. The exponential model presents a very small value at the beginning comparing with the other models and later it increases exponentially. Growth models that incorporate few variables to describe temporal disease dynamics have a good performance; however, these kind of models sometimes do not satisfy the acquiring process of key characteristics because they frequently ignore relevant variables that affect the epidemic development (Xu 2006), e.g. host growth, fluctuating environmental condition, length of latent and infectious period, etc. Disease progress curves are used to compare control measures, effect of environment on disease development, prediction of future disease development, disease forecasting for improved control, predict disease severity over host growth stages. Most commonly used growth models are Exponential, Logistic and Gompertz (Nutter 2007; Xu 2006). Thus, in the present investigation the Logistic and Gompertz models hold true. Thus, the nature of the problem and the epidemiologist necessities determine the mathematical tool to be used and the variables to be included into the model.

Prevailing minimum temperature coupled with morning relative humidity accompanied with the rainfall during 29th to 31th SMW were predisposing weather factors for conidia germination and further sporulation. Similar conclusions were reached by (Dodd et al. 1991; Fitzell et al. 1984) who found that $C$. gloeosporioides requires free water or relative humidity
Fig. 11 Correlation between mango anthracnose severity and weather parameters (2018)

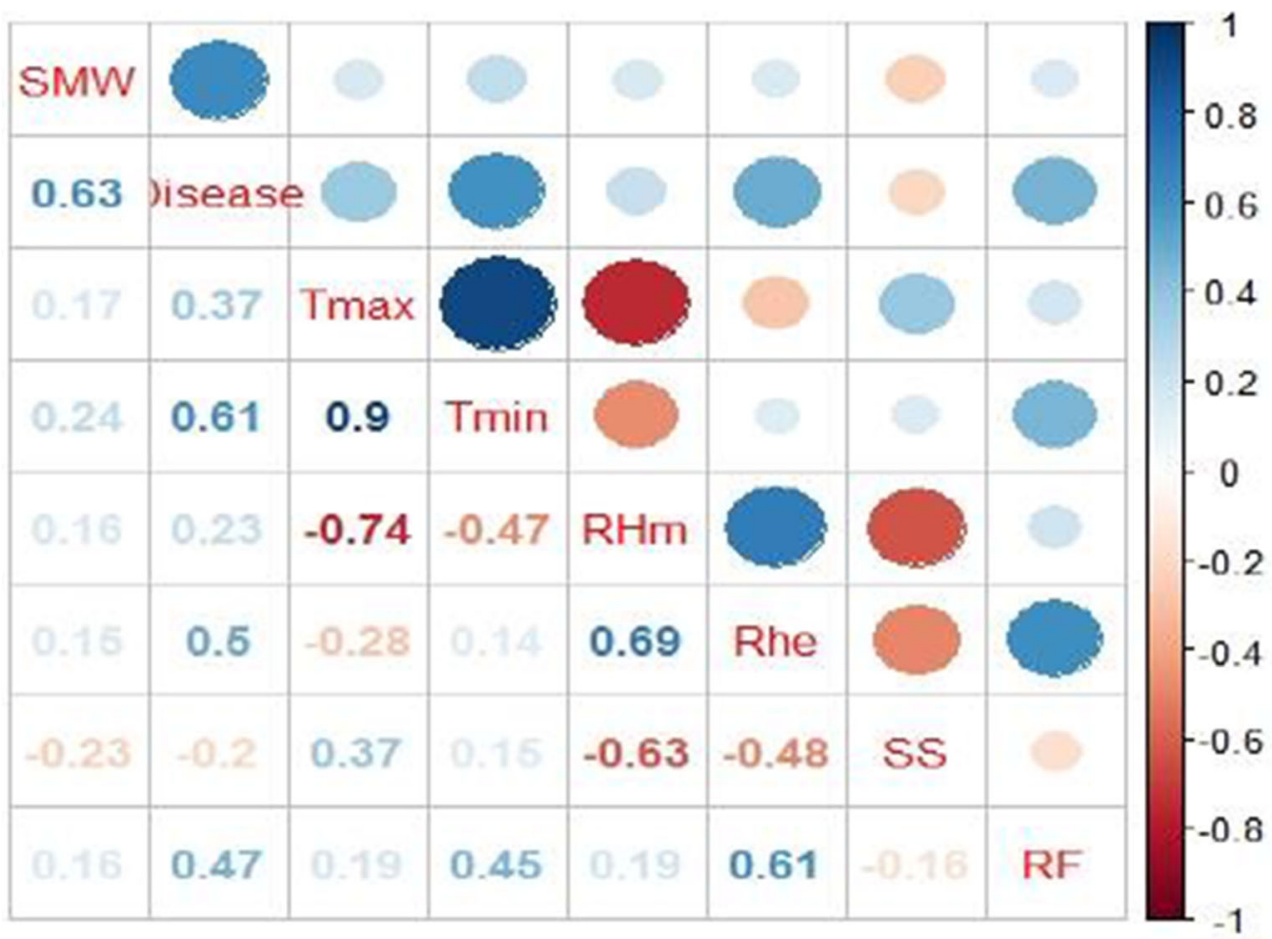


Fig. 12 Correlation between mango anthracnose severity and weather parameters (2013-18)

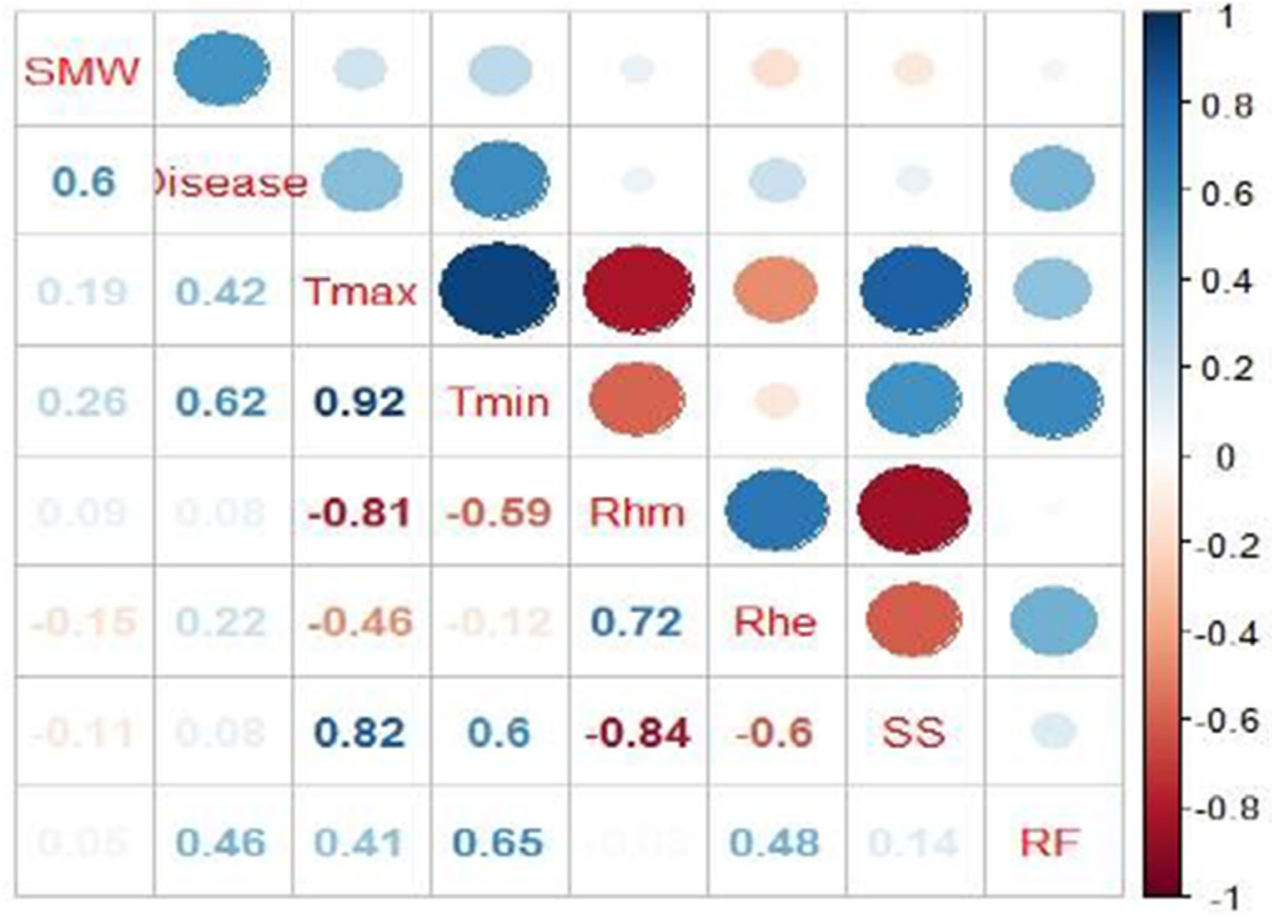

above $95 \%$ for conidial germination and appressorium formation which corroborate present study. Pandey et al. (2012) reported that $C$. gloeosporioides conidia can grow maximum under the temperature ranging 28 to $32{ }^{\circ} \mathrm{C}$. Similarly, maximum conidial germination and sporulation was observed at $28{ }^{\circ} \mathrm{C}$ in C. gloeosporioides isolates by Nelson et al. (2015), Sangeetha and Rawal (2010), Estrada et al. (2000), which is in agreement with the present findings. Minimum temperature followed by rainfall has significant positive correlation with disease severity in each of the years 2013, 2014, 2015, 2017 and 2018. The regression model based on pooled data performed better than other regression model of each individual year with highest adjusted $\mathrm{R}^{2}$ (coefficient of determinant) value explaining the effects of minimum temperature, morning relative humidity and rainfall on the anthracnose severity. It is further added that decline in anthracnose or negative periodical progression was due to defoliation of infected leaves and noncongenial prevailing weather condition.(Figs.7, 8, 9, 10, 11 and 12)

Thus, it is inferred from above results that, antecedent meteorological data on different weather variables viz. minimum temperature, morning relative humidity and rainfall can reliably be used to foretell the disease severity through logistic model for effective mitigation of rapid build-up of inoculum and timely proper prophylactic management practices can be adopted by farmers, by providing/ offering mango growers and decision/policy makers with a prior knowledge of consequence of anthracnose incursions and impact of management strategies.

Table 5. Regression equation for relationship between mango anthracnose and weather parameters

\begin{tabular}{|c|c|c|c|c|c|c|c|c|c|}
\hline Disease & Constant & Tmax & Tmin & Rhm & Rhe & SS & $\mathrm{RF}$ & $\mathrm{R}^{2}$ & Adj. $R^{2}$ \\
\hline 2013 & $-2.801 *(3.861)$ & - & $1.536 * *(0.234)$ & - & - & $3.33 * *(0.699)$ & - & 0.658 & 0.628 \\
\hline 2014 & $-105.81 * *(18.68)$ & - & $2.485 * *(0.298)$ & $1.244 * *(0.244)$ & $\begin{array}{l}-0.394 * * \\
(0.019)\end{array}$ & - & $-0.365 * *(0.115)$ & 0.782 & 0.741 \\
\hline 2015 & $-52.417 *(21.281)$ & - & $1.659 * *(0.336)$ & $0.456 *(0.206)$ & - & - & - & 0.526 & 0.485 \\
\hline 2017 & $-81.192 * *(15.38)$ & - & $1.794 * *(0.253)$ & $0.958 * *(0.202)$ & $\begin{array}{l}-0.356^{*} \\
(0.141)\end{array}$ & - & - & 0.728 & 0.687 \\
\hline 2018 & $-63.812 * *(12.096)$ & - & $1.379 * *(0.189)$ & $0.658 * *(0.123)$ & - & - & - & 0.718 & 0.694 \\
\hline Pooled & $-105.033 * *(16.843)$ & - & $2.445 * *(0.331)$ & $0.972 * *(0.159)$ & - & - & $-0.258 * *(0.088)$ & 0.777 & 0.747 \\
\hline
\end{tabular}

Note: *Regression coefficient denote the effect of weather parameter on anthracnose, whereas **Standard error for accuracy of regression parameters 
Acknowledgements Authors are thankful to Prof and Head, Department of Horticulture CCS HAU Hisar-India for providing necessary facilities. We declare that there is no conflict of interest in the manuscript.

\section{Compliance with ethical standards}

Conflict of interest The authors declare that there is no conflict of interest in the manuscript.

Open Access This article is licensed under a Creative Commons Attribution 4.0 International License, which permits use, sharing, adaptation, distribution and reproduction in any medium or format, as long as you give appropriate credit to the original author(s) and the source, provide a link to the Creative Commons licence, and indicate if changes were made. The images or other third party material in this article are included in the article's Creative Commons licence, unless indicated otherwise in a credit line to the material. If material is not included in the article's Creative Commons licence and your intended use is not permitted by statutory regulation or exceeds the permitted use, you will need to obtain permission directly from the copyright holder. To view a copy of this licence, visit http://creativecommons.org/licenses/by/4.0/.

\section{References}

Arauz LF (2000) Mango anthracnose: economic impact and current options for integrated management. Plant Dis 84:600-611

Dodd J. C, Estrada A. B, Matcham, J, Jeffries P, Jeger, M. J(1991) The effect of climatic factors on Colletotrichum gloeosporioides, causal agent of mango anthracnose, in the Philippines. Plant Pathol.40: $568-575$

Dodd JC, Estrada A, Jeger M (1992) Epidemiology of C. gloeosporioides in the tropics. In: Bailey JA, Jeger MJ (eds) Colletotrichum: biology, pathology and control. CAB International, Wallingford, pp 308-325

Estrada AB, Dodd JC, Jeffries P (2000) Effect of humidity and temperature on conidial germination and appressorium development of two Philippine isolates of the mango anthracnose pathogen Colletotrichum gloeosporioides. Plant Pathol 49:608-618
Fitzell RD, Peak CM, Darnell RE (1984) A model for estimating infection levels of anthracnose disease of mango. Ann Appl Biol 104:451-458

Nelson BL, Lima WG, Tovar-Pedraza JM, Michereff Marcos SJ, Câmara PS (2015) Comparative epidemiology of Colletotrichum species from mango in northeastern Brazil. Eur J Plant Pathol 141:679-688

Nutter FW Jr (2007) The role of plant disease epidemiology in developing successful integrated disease management programmes. pp. 45 79. In: General concepts in integrated pest and disease management. A. Ciancio and K. G. Mukerji, Ed. Springer-Verlag, Dordrecht, The Netherlands

Nutter FW, Parker SK (1997) Fitting disease progress curves EPIMODEL. In: Francl LJ, Neher DA (eds) Exercises in plant disease epidemiology. APS Press, St. Paul, pp 24-28

Pandey A, Yadava LP, Mishra RK, Pandey BK, Muthukumar M, Chauhan UK (2012) Studies on the incident and pathogenesis of Colletotrichum gloeosporioides Penz. Causes anthracnose of mango. Int J Sci Nat 3:220-232

Ploetz RC, Benscher D, Vázquez A, Colls A, Nagel J, Schaffer B (1996) Mango decline: research in Florida on an apparently wide-spread disease complex. Proc. Int. Mango Sympos., 5th. Acta Hortic 455: $547-553$

Prakash O (2004) Diseases and disorders of mango and their management. In: Naqvi SAMH (ed) Diseases of fruits and vegetables: diagnosis and management. Kluwer, Dordrecht, pp 511-619

Sangeetha CG, Rawal RD (2010) Temperature requirement of different isolates of Colletotrichum gloeosporioides isolated from mango. Afr J Biotechnol 9(21):3086-3090

SantosFilho HP, Matos AP (2003) Doençasdamangueira. In: Freire FCO, Cardoso JE, Viana FMP (eds) Doenças de fruteiras tropicais de interesse agroindustrial. Embrapa Informação Tecnológica, Brasília, pp 435-491

Van der Plank J. E (1963) Plant diseases. Epidemics and Control. Academic Press, New York, U.S.A.

Van Maanen A, Xu XM (2003) Modelling plant disease epidemics. Eur J Plant Pathol 109:669-682

$\mathrm{Xu}$ X (2006) Modeling and interpreting disease progress in time. In: Cooke BM, Gareth Jones D, Kaye B (eds) The epidemiology of plant disease. Springer, Dordrecht, The Netherlands, pp 215-238

Zadoks J. C, Schein R. D (1979) Epidemiology and plant disease management. Oxford University Press, New York, U.S.A. 